\title{
PREPARATION, CHARACTERIZATION, AND THERMAL STABILITY OF $\mathrm{B}_{2} \mathrm{O}_{3}$ - $\mathrm{ZrO}_{2}$
}

\author{
Theresia Debora Simbolon ${ }^{1 *}$, Risfidian Mohadi ${ }^{1}$ \\ Department of Chemistry, Faculty of Mathematic and Natural Sciences, Sriwijaya University \\ Corresponding Author Email: theresiadeb@gmail.com
}

\begin{abstract}
Synthesis of the borate-based compound with $\mathrm{ZrOCl}_{2}$ to form $\mathrm{B}_{2} \mathrm{O}_{3}-\mathrm{ZrO}_{2}$ has been conducted. The compound was characterized by FT-IR spectrophotometer, X-ray diffraction, acidity and thermal stability test. The results showed that the FT-IR main vibration spectrum of $\mathrm{B}_{2} \mathrm{O}_{3}-\mathrm{ZrO}_{2}$ compound has appeared at wave number $401.2 \mathrm{~cm}^{-1}$ for $\mathrm{Zr}-\mathrm{O}$ bonding vibration, $617.2 \mathrm{~cm}^{-1}$ for B-O-B bonding vibration and $910.4 \mathrm{~cm}^{-1}$ for $\mathrm{B}-\mathrm{O}$ bonding vibration. The XRD diffraction pattern shows $\mathrm{B}_{2} \mathrm{O}_{3}-\mathrm{ZrO}_{2}$ compound has an amorphous structure. The FT-IR spectrum after saturated with ammonia and potentiometric titration indicates that the compound of $\mathrm{B}_{2} \mathrm{O}_{3}-\mathrm{ZrO}_{2}$ has acidic properties with a strong level of acidity. Thermal stability test shows that the $\mathrm{B}_{2} \mathrm{O}_{3}-\mathrm{ZrO}_{2}$ compounds have high stability on temperature with increasing crystallinity after the compound was heated at $700{ }^{\circ} \mathrm{C}$.
\end{abstract}

Keywords: $\mathrm{B}_{2} \mathrm{O}_{3}-\mathrm{ZrO}_{2}$, impregnation, thermal stability.

\section{INTRODUCTION}

Non-metal doping of transition metal oxides is an interesting topic to develop novel materials based metal oxides. Non-metal doping with metal oxides has unique properties such as optical and electronic properties, crystal structures, and also the thermal stability of these compounds. The application of these materials is also can be used in many fields including catalysis, sensor, and photocatalysis (Marschall and Wang, 2014). One of the interesting element is boron due to metalloid properties and Lewis acidity of this element and compounds (Slack and Morgan, 2015). Boric acid is solid compound and has been applied as catalyst or support catalyst. The catalytic properties of boric acid are interesting due to chemical characters such as stability under high temperature and high stability. On the other hand, the acidity of boric acid is relatively low thus there is a limitation for application such as reaction with high acidity catalyst. In order to increase the acidity of boric acid, thus modification of boric acid is vital.

The various method has been applied for modification of boric acid to increase the acidity properties such as grafting, impregnation, and support with other material like metal oxides. For example, Osiglio and Blanco (2012) was prepared zirconium-boric acid and resulted in increased surface area of zirconium-borate after impregnation process. If surface area of materials is increased thus the catalytic activity of these materials is also increased due to reactivity of active side in materials. Boric acid supported metal oxide such as zirconium has been synthesis by Matsuhashi et.al (1994). Boric acid supported with zirconium oxide with $30 \%$ boric acid content can increase the acidity of boric acid to super acid. Super acid is the class of material with acidity is high than sulfuric acid. Boric acid supported zirconium oxide synthesized by Matsuhasi et.al was applied as an efficient catalyst for decomposition of eth-

\section{Article History}

Received: 5 September 2016

Received in revised form: 21 February 2017

Accepted: 23 March 2017

DOI: $10.26554 /$ sti.2017.2.2.56-58

(C)2017 Published under the term of the CC BY NC SA license anol to ethylene. This material has Hammett acidity value closed to -13 and acid than conventional acids such as nitric acid, hydrochloric acid, and sulfuric acid. Boric acid supported zirconium oxide also was prepared by Patil et.al (2002). Borat-zirconium from preparation has high thermal stability and can be used as a catalyst for high-temperature condition reactions. Previous research also reported that silica oxide was used as a support of boric acid to form $\mathrm{B}_{2} \mathrm{O}_{3}-\mathrm{SiO}_{2}$ (Fitriana and Lesbani, 2017). This compound has high thermal stability up to $700{ }^{\circ} \mathrm{C}$ without changes structural properties. In this research, material $\mathrm{B}_{2} \mathrm{O}_{3} / \mathrm{ZrO}_{2}$ was prepared in order to increase the properties of mixed boron compounds. Material $\mathrm{B}_{2} \mathrm{O}_{3} / \mathrm{ZrO}_{2}$ was characterized by FTIR, XRD analyses, and acidity measurement by ex-situ analysis and potentiometric titration.

\section{EXPERIMENTAL SECTION}

\section{Chemicals and Equipments}

Chemicals are used directly after purchased from Merck and Sigma Aldrich such as zirconium oxychloride, boric acid, ammonia, acetonitrile, and n-butylamine. Water was supplied from Integrated Research Laboratory using Purite water purification system.

The analysis was conducted using Shimadzu FTIR Prestige-21 with $\mathrm{KBr}$ pellet, and the sample was scanning of wavenumber 300 $4000 \mathrm{~cm}^{-1}$. XRD powder pattern was conducted using Shimadzu X-Ray LabX type 6000 and sample were scanning 1 deg. min $^{-1}$.

\section{Preparation and Characterization of $\mathrm{B}_{2} \mathrm{O}_{3}-\mathrm{ZrO}_{2}$}

Preparation of $\mathrm{B}_{2} \mathrm{O}_{3}-\mathrm{ZrO}_{2}$ was conducted according to Patil et.al (2014) with slight modification as follow. Zirconia oxochloride $(48.3 \mathrm{~g}$ ) was mixed with $110 \mathrm{~mL}$ water and $10 \mathrm{~mL}$ ammonia. The mixture was stirred for 30 minutes. $\mathrm{pH}$ of the mixture was checked. If $\mathrm{pH}$ mixture is less than ten thus ammonia was added to reach $\mathrm{pH} 10$. The mixture was vacuum filtered and dry at 100 ${ }^{\circ} \mathrm{C}$ overnight (solid A). A separate experiment was conducted as follow. Boric acid $(9.2 \mathrm{~g}$ ) was dissolved in $200 \mathrm{~mL}$ water. Into this solution, solid A was added with slowly stirring for 1 hour. The mixture was vacuum filtered and dry at $100{ }^{\circ} \mathrm{C}$ for overnight. Characterization of material was conducted using FTIR spectroscopy, 


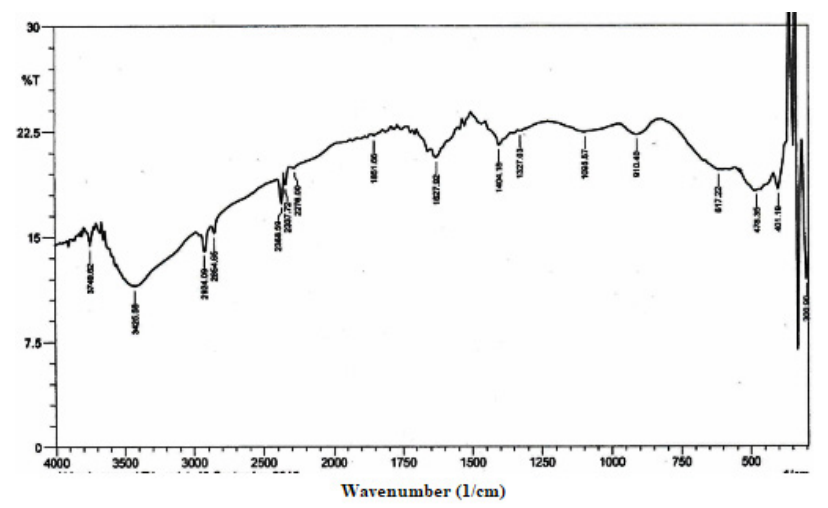

Figure 1. FTIR spectra of $\mathrm{B}_{2} \mathrm{O}_{3}-\mathrm{ZrO}_{2}$.

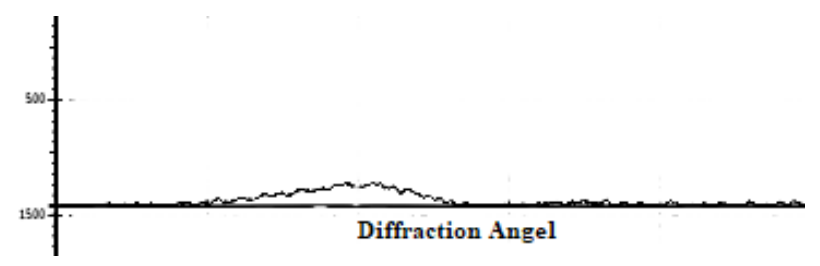

Figure 2. XRD powder patterns of $\mathrm{B}_{2} \mathrm{O}_{3}-\mathrm{ZrO}_{2}$.

$\mathrm{X}$-ray powder analysis, and acidity measurement using potentiometric titration.

\section{RESULTS AND DISCUSSION}

Compound $\mathrm{B}_{2} \mathrm{O}_{3}-\mathrm{ZrO}_{2}$ was obtained as white bulk solid material. Characterization using FTIR spectroscopy as shown in Figure 2 demonstrated that vibration of boron and zirconia was appeared at wavenumber less than $1000 \mathrm{~cm}^{-1}$ (Ford, 2009). All peaks in the IR spectrum can be distinguished clearly although the spectrum is a little boardened. The main vibration of $\mathrm{B}_{2} \mathrm{O}_{3}-\mathrm{ZrO}_{2}$ is appeared at $401.2 \mathrm{~cm}^{-1}$ (v Zr-O), $478.4 \mathrm{~cm}^{-1}$ (v O-Zr-O), $617.2 \mathrm{~cm}^{-1}$ (v B-O-B), and $910.5 \mathrm{~cm}^{-1}$ ( $\left.\cup \mathrm{B}-\mathrm{O}\right)$. Other vibrations are identified as $\mathrm{Zr}-\mathrm{OH}$ at $1404.2 \mathrm{~cm}^{-1}$ and $3425.6 \mathrm{~cm}^{-1}$ as $\mathrm{O}-\mathrm{H}$ vibration. Vibration at 3425.6 $\mathrm{cm}^{-1}$ was broad and sharp due to synthetic of material $\mathrm{B}_{2} \mathrm{O}_{3}-\mathrm{ZrO}_{2}$ was conducted in water. The FTIR spectrum indicated that material $\mathrm{B}_{2} \mathrm{O}_{3}-\mathrm{ZrO}_{2}$ was formed but to clearly identified thus XRD analysis was conducted. XRD powder pattern of $\mathrm{B}_{2} \mathrm{O}_{3}-\mathrm{ZrO}_{2}$ is shown in Figure 2.

XRD powder pattern of $\mathrm{B}_{2} \mathrm{O}_{3}-\mathrm{ZrO}_{2}$ showed that broad dif-

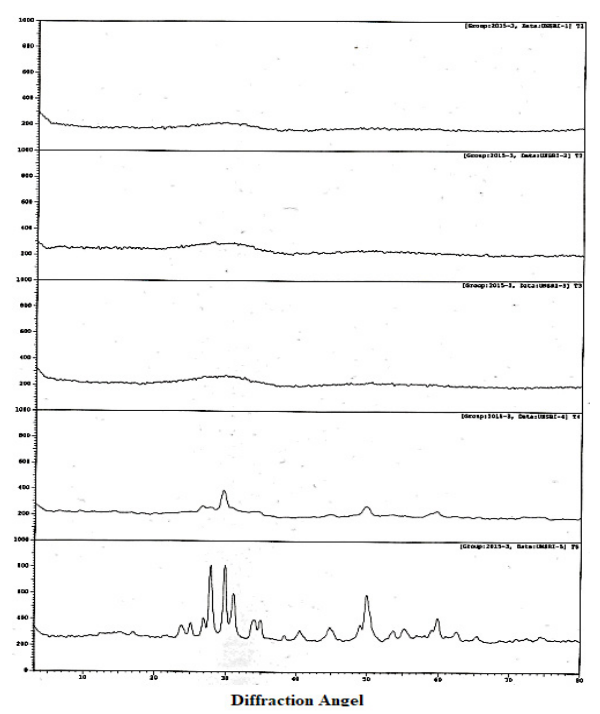

Figure 3. Diffraction patterns of $\mathrm{B}_{2} \mathrm{O}_{3}-\mathrm{ZrO}_{2}$ at various temperatures $\mathrm{A}\left(300^{\circ} \mathrm{C}\right) \mathrm{B}\left(400^{\circ} \mathrm{C}\right), \mathrm{C}\left(500^{\circ} \mathrm{C}\right), \mathrm{D}\left(600^{\circ} \mathrm{C}\right)$ dan $\mathrm{E}\left(700^{\circ} \mathrm{C}\right)$. fraction peaks between 20-30 deg. Material $\mathrm{B}_{2} \mathrm{O}_{3}-\mathrm{ZrO}_{2}$ is amorphous and no crystallographic parameter was identified. On the other hand, diffraction of zirconium oxide and boron oxide have crystallographic parameter, which was identified from crystalline sharp peaks. Zirconia oxide has main diffraction at 18-19 deg, 20$25 \mathrm{deg}$, and 28-33 deg. Boron oxide has diffraction at $15 \mathrm{deg}$ and $28 \mathrm{deg}$ (Atasoy, 2010). If material $\mathrm{B}_{2} \mathrm{O}_{3}-\mathrm{ZrO}_{2}$ formed according to IR spectrum, then XRD pattern of $\mathrm{B}_{2} \mathrm{O}_{3}-\mathrm{ZrO}_{2}$ should be clearly identified. Probably due to high water content in the material $\mathrm{B}_{2} \mathrm{O}_{3}-\mathrm{ZrO}_{2}$ then diffraction peak was broad. Although material $\mathrm{B}_{2} \mathrm{O}_{3}-\mathrm{ZrO}_{2}$ was kept at $100{ }^{\circ} \mathrm{C}$ overnight, but crystalline water cannot be removed by this way. Thus experiment was conducted using thermal stability test. Thermal stability test was conducted in range temperature at 300-700 to remove completely water from the material. Material was then characterized using XRD analysis as shown in Figure 3.

Figure 3 showed that increasing temperature treatment could increase the crystallinity of material $\mathrm{B}_{2} \mathrm{O}_{3}-\mathrm{ZrO}_{2}$. The temperature at $600{ }^{\circ} \mathrm{C}$ shows diffraction peak at $30 \mathrm{deg}$. Heating material $\mathrm{B}_{2} \mathrm{O}_{3}-$ $\mathrm{ZrO}_{2}$ at $700{ }^{\circ} \mathrm{C}$ was also increased crystallinity. Several peaks diffraction were detected after heating temperature $700{ }^{\circ} \mathrm{C}$. Diffraction at 25-32 deg, $40 \mathrm{deg}, 45 \mathrm{deg}, 50 \mathrm{deg}, 55-54 \mathrm{deg}$, and $60 \mathrm{deg}$ was detected. Boric oxide was assigned at diffraction 25-50 deg and zirconium oxide was identified at diffraction 54-60 deg. From this results, the assumption of decreasing crystallinity due to water content as possible. This material $\mathrm{B}_{2} \mathrm{O}_{3}-\mathrm{ZrO}_{2}$ was successfully synthesis at two phases i.e. amorphous phase at low temperature and crystalline phase at high temperature.

To investigate other properties of material $\mathrm{B}_{2} \mathrm{O}_{3}-\mathrm{ZrO}_{2}$, thus acidity measurement was carried out using qualitative and quantitative analyses. Qualitative analysis of acidity was conducted as ex-situ using ammonia as probe and material were analyzed by FTIR as shown in Figure 4.

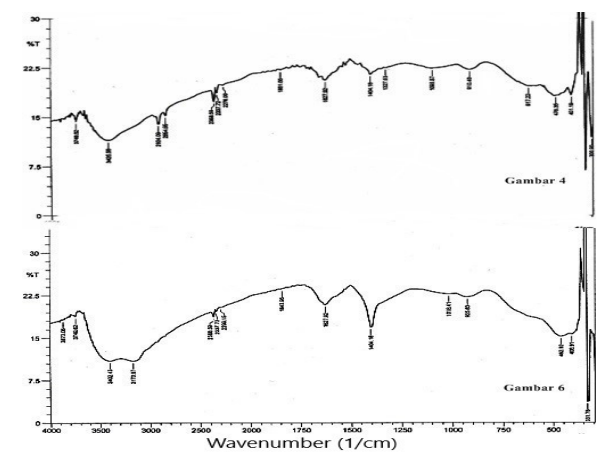

Figure 4. FTIR spectrum of $\mathrm{B}_{2} \mathrm{O}_{3}-\mathrm{ZrO}_{2}(\mathrm{~A})$ and $\mathrm{B}_{2} \mathrm{O}_{3}-\mathrm{ZrO}_{2}$ after ex-situ exposes with ammonia (B).

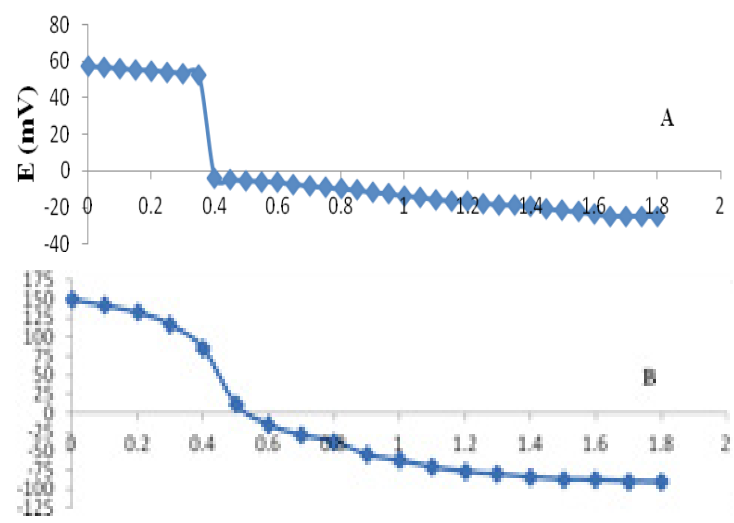

Figure 5. Potentiometric titration curve of $\mathrm{H}_{3} \mathrm{BO}_{3}(\mathrm{~A})$ and material $\mathrm{B}_{2} \mathrm{O}_{3} / \mathrm{ZrO}_{2}$ (B). 
Vibration at wavenumber $1404.2 \mathrm{~cm}^{-1}$ and $1627.9 \mathrm{~cm}^{-1}$ was appeared in material $\mathrm{B}_{2} \mathrm{O}_{3}-\mathrm{ZrO}_{2}$ after ammonia exposes. These vibrations are assigned as ammonium ion which was chemisorption of Bronsted acid. Bronsted acid was detected and produced due to hydration of boric species (Sivaev and Bregadze, 2014). This material $\mathrm{B}_{2} \mathrm{O}_{3}-\mathrm{ZrO}_{2}$ is classified as acid material. The strength of acidity of $\mathrm{B}_{2} \mathrm{O}_{3}-\mathrm{ZrO}_{2}$ was measured using potentiometric titration. Titration curve of boric acid and $\mathrm{B}_{2} \mathrm{O}_{3}-\mathrm{ZrO}_{2}$ is shown in Figure 5 .

Titration was carried out using n-buthylamine. Titration curve in Figure 5 showed that $\mathrm{H}_{3} \mathrm{BO}_{3}$ has potential $57.2 \mathrm{mV}$ and material $\mathrm{B}_{2} \mathrm{O}_{3} / \mathrm{ZrO}_{2}$ has potential $149.3 \mathrm{mV}$. These results show material $\mathrm{B}_{2} \mathrm{O}_{3} / \mathrm{ZrO}_{2}$ has strong acidity level than boric acid (Yu et.al, 2016). Thus material $\mathrm{B}_{2} \mathrm{O}_{3} / \mathrm{ZrO}_{2}$ has acidity more than starting material and can be used as acid catalyst candidate for various chemical reaction.

\section{CONCLUSION}

Material $\mathrm{B}_{2} \mathrm{O}_{3}-\mathrm{ZrO}_{2}$ can be easily prepared and has high crystallinity high temperature. Crystal structure of $\mathrm{B}_{2} \mathrm{O}_{3}-\mathrm{ZrO}_{2}$ showed that amorphous phase at low temperature and crystal phase at high temperature. Material $\mathrm{B}_{2} \mathrm{O}_{3}-\mathrm{ZrO}_{2}$ has high acidity than boric acid as starting material.

\section{REFERENCES}

Atasoy. A. (2010). The Aluminothermic Reduction of Boric Acid. Internationa Journal of Refractory Metals and Hard Materials, 25,5, 616-622.

Fitriana. W., Lesbani. A. (2017). Preparation, Characterization, and
Thermal Stability of $\mathrm{B}_{2} \mathrm{O}_{3}-\mathrm{SiO}_{2}$. Science and Technology Indonesia, 2, 22-24.

Ford. T.A. (2009). The Vibrational Spectra of the Boron Halides and Their Molecular Complexes. Part 12: The Complexes of Boron Trifluoride with Methyl Fluoride and Methyl Chloride. An abinitio Study. Journal of Molecular Structure:THEOCHEM, 897, 145-148.

Patil P.T., Malshe. K.M., Kumar. P., Dongare. M.K., Kemnitz. E. (2002). Benzoylation of Anisole Over Botare Zirconia Solid Acid Catalyst. Catalysis Communations, 3, 411-416.

Marschall. R., Wang. L. (2014). Non-metal doping of Transition Metal Oxides for Visible Light Photocatalysis. Catalysis Today, 225, 111-135.

Matsuhashi. H., Kato. K., Arata. K. (1994). Synthesis of Solid Superacid of Borate Supported on Zirconium Oxides. Studies in Surface Science and Catalysis, 90, 251-256.

Osiglio. L., Blanco. M. (2012). Effect of the Addition of Boric Acid to Zirconia Synthesized Employing Pore-Forming Agents. Procedia Materials Science, 1, 491-498.

Sivaev. I.B., Bregadze. V.I. (2014). Lewis Acidity of Boron Compounds. Coordination Chemistry Reviews, 270-271, 75-88.

Slack. G.A., Morgan. K.E. (2015). Crystallography, Semiconductivity, Thermoelectricity, and Other Properties of Boron and Its Compounds, Especially B O. Solid State Sciences, 47, 43-50.

Yu. K., Kumar. N., Aho. A., Roine. J., Heinmaa. I., Yu Murzin. D., Ivaska. A. (2016). Determination of Acid Sites in Porous Aluminosilicates Solid Catalysts for Aqueous Phase Reactions Using Potentiometric Titration Method. Journal of Catalysis, $335,117-124$. 